\title{
Awareness and practice regarding cervical cancer screening among women visiting a tertiary hospital of Kathmandu
}

\section{Parajuli P', Paudel N², Dahal S ${ }^{3}$}

${ }^{1}$ Puspa Parajuli, Assistant Professor, ${ }^{2}$ Narayani Paudel, Associate Professor, Department of Nursing, Kathmandu Medical College Teaching Hospital; ${ }^{3}$ Sunita Dahal, Lecturer, Norvic Institute of Nursing Education, Kathmandu, Nepal.

\begin{abstract}
Background: Cervical cancer is the leading female cancer in Nepal. Fortunately, it is preventable by detecting precancerous lesions and by various screening tools for early invasive cancers. Screening can be possible if women are aware of the problem. Despite the existence of effective screening using Pap smear, the uptake of screening is poor. Objectives: The objective of this study was to assess the awareness and practice regarding cervical cancer screening among women visiting tertiary hospital.

Methodology: A descriptive cross - sectional study was conducted to assess the awareness and practice regarding cervical cancer screening among women attending in gynaecological outpatient department of Kathmandu Medical College Teaching Hospital. A total of one hundred and fifty two women were selected purposively for the study. Structured questionnaire was designed and data collection was done through face to face interview technique during the period of September to November 2018. The collected data were analyzed by using Statistical Package for Social Science version 20.

Results: Among 152 respondents, majority of the respondents (59.2\%) were aware that multiple sexual partners is one of the risk factors of cervical cancer. $38.8 \%$ were aware that cervical cancer can be prevented by regular cervical screening. Majority of the respondents: 152 (44.7\%) had given correct response regarding meaning of cervical cancer screening and $42.8 \%$ were aware of Pap smear test for cervical screening. Only 31.6\% had performed cervical cancer screening at least once. Overall mean percentage knowledge was 3.08 with SD 0.96.There was weak correlation between knowledge and practice.

Conclusion: This study concluded that majority of respondents had inadequate knowledge and practice regarding cervical cancer screening. Thus, cervical cancer screening health camps and awareness program should be conducted at community to national level for women, to increase the level of knowledge and practice regarding cervical cancer screening.
\end{abstract}

Key words: Awareness; Cervical cancer; Practice; Screening

DOI: https://doi.org/10.3126/jkmc.v8i2.28169

\section{INTRODUCTION}

Con ervical cancer is the third most common cancer among women and the fourth leading cause of cancer deaths in females worldwide. More than $85 \%$ of these cases and deaths occur in developing countries. South-east Asian countries like India, Nepal and Srilanka jointly contribute to nearly one-third of the global cervical cancer burden ${ }^{1}$.

\section{Address for correspondence}

Ms. Puspa Parajul

Assistant Professor, Nursing Department

Kathmandu Medical College, Kathmandu, Nepal

E-mail: puspaparajulidahal@gmail.com
Infection with Human Papilloma Virus (HPV) types 16 and 18 cause $75 \%$ of cervical cancer globally. The other risk factors include tobacco consumption, multiple sexual partners, early age of sexual intercourse, increasing parity, prolonged use of oral contraceptive pills, sexually transmitted diseases ${ }^{2}$.

Cervical cancer is a malignant neoplasm arising from cells originating in cervix uteri. It may be completely asymptomatic in early stages ${ }^{3}$. In advanced stages it may present as persistent pelvic pain, unexplained weight loss, bleeding between periods, unusual vaginal discharge, bleeding and pain after sexual intercourse ${ }^{4}$. 
The introduction of different screening techniques for cervical cancer has led to a significant reduction in morbidity and mortality from the disease. Various screening techniques have been introduced for early detection of cervical cancer in Nepal. For instance, Papanicolaou smear screening has been reported to be a good method for detecting early cervical cancer ${ }^{5}$.

Cervical cancer is the most common cancer seen in Nepal. As per the findings of Hospital Based Cancer Registry from 2003-2012, 6249(20.9\%) new cervical cancer cases have been diagnosed which is the highest among the total female new cancer cases ${ }^{6}$. Though cervical cancer screening is available in some areas of Nepal, screening is mostly conducted when women come to the hospital for other medical problems and sometimes only when women present with symptoms. Despite the evidence that universal coverage is important, women in Nepal are not routinely screened before symptoms appear pradhan ${ }^{7}$. Screening is underutilized in the developing countries due to a number of factors like poor educational background, lack of knowledge regarding the availability and benefits of screening, lack of information from part of health care workers, affordability of screening tools by the individual, cultural barriers, unavailability of facilities at all health centers and the like. Of these, lack of awareness and attitude, wrong beliefs about the disease and screening for it are one of the major factors.

\section{METHODOLOGY}

A descriptive cross - sectional study was conducted to assess the awareness and practice regarding cervical cancer screening among women. Ethical approval for the study was obtained from the institutional review committee of Kathmandu Medical College Teaching Hospital (KMCTH).One hundred fifty two women, attending in Gynaecological Outpatient Department of KMCTH were purposively selected for the study. Permission for data collection was taken from head of the department of Obstetrics / Gynaecology and written informed consent was taken from each respondents. Face to face interview technique was used to collect necessary data by using predesigned structured questionnaire. The data collection period was from September to November 2018. Collected data were coded and analyzed by using Statistical Package for Social Sciences (SPSS) 20 version. Categorical variables were described using frequency distribution and percentages. Continuous variables were expressed by means and standard deviations. Chi - square test was used for analysis for association between demographic variables with knowledge of Cervical Cancer Screening.
The level of knowledge score is categorized on the basis of two sections which include inadequate and adequate. The score $\geq 50 \%$ denote adequate level of knowledge and $<50 \%$ denotes inadequate level of knowledge. Practice score was categorized as adequate practice (score $\geq$ mean score i.e., $\geq 1.29$ ) and inadequate practice (score < mean score i.e., < 1.29). Pearson's correlation and coefficient was used to see the correlation between knowledge and practice.

\section{RESULTS}

Socio demographic characteristics of the respondents are presented in Table 1. A majority of the respondents, $44.1 \%$ were in between the age of $30-40$ years with overall mean 32.24 . Majority of the respondents, $83.6 \%$ were Hindu and more than half, $51.3 \%$ of respondents had completed secondary level of education. Regarding occupation, majority of the respondents, $50.7 \%$ were house maker and only $2.6 \%$ respondents had participated in awareness program of cervical screening.

Awareness regarding cervical cancer; all of the respondents had heard about cervical cancer. The most common source of information on cervical cancer was media. Only a few respondents got information from health professional. Regarding risk factors of cervical cancer, more than half of the respondents (59.2\%) were aware that multiple sexual partners is the risk factor of cervical cancer. Similarly, $57.9 \%$ and $34.2 \%$ were aware that poor personal hygiene and having sexual transmitted infection are risk factors of cervical cancer respectively. One third (33.6\%)of the respondents answered that early age of sexual intercourse and cigarette smoking( 11.8) are the risk factors of cervical cancer. Regarding sign and symptoms of cervical cancer, only $41.4 \%$ of the respondents were aware that increase foul smelling vaginal discharge is the main sign and symptom of cervical cancer. Regarding preventive measure of cervical cancer, majority (54.6\%) of the respondents were aware that maintaining personal hygiene is a preventive measure of cervical cancer. Similarly, 38.8\% respondents were aware that cervical cancer can be prevented by regular cervical screening (Table 2).

Awareness regarding cervical cancer screening: Out of 152 respondents, the most common sources of information on cervical cancer screening were media and relatives. Only $17.4 \%$ of the respondents got information from health professional. Below half (42.8\%) of the respondents had given correct response regarding meaning of cervical cancer screening. Majority (39.4\%) of the respondents were aware that Pap smear is the 
screening test for cervical cancer and only $17.1 \%$ of the respondents had awareness on start of cervical screening after sexual active. Only $5.9 \%$ of the respondents were aware that screening should be done every three years and $21.7 \%$ of the respondents were aware on Pap test should be done 10 - 20 days of menstruation (Table 3 ).

Practice regarding cervical cancer screening: Out of 48 respondents, only $31.6 \%$ had performed cervical cancer screening at least once. Likewise, $60.4 \%$ respondents had performed cervical cancer screening one time, $22.9 \%$ two times and $16.7 \%$ three times. Only $54.2 \%$ respondents had performed cervical screening for prevention and $41.7 \%$ on a health worker's recommendation. Only $17.1 \%$ had adequate knowledge regarding cervical cancer screening with mean \pm SD $3.08 \pm 0.96$. Among 48 respondents, only $29.2 \%$ had adequate practice regarding cervical cancer screening.

Table 1: Socio demographic characteristics of the respondents $(n=152)$

\begin{tabular}{|c|c|c|}
\hline Variables & Frequency & Percentage (\%) \\
\hline \multicolumn{3}{|l|}{ Age (years) } \\
\hline \multicolumn{3}{|l|}{$\leq 20$} \\
\hline $21-30$ & 3 & 2.0 \\
\hline $31-40$ & 65 & 42.8 \\
\hline $41-50$ & 67 & 44.1 \\
\hline Mean $\pm S . D=32.24 \pm 6.621$ & 17 & 11.2 \\
\hline \multicolumn{3}{|l|}{ Religion } \\
\hline Hindu & 127 & 83.6 \\
\hline Buddhist & 20 & 13.2 \\
\hline Christian & 5 & 3.2 \\
\hline \multicolumn{3}{|l|}{ Education } \\
\hline Non - formal education & 3 & 2 \\
\hline Primary & 30 & 19.7 \\
\hline Secondary & 48 & 31.6 \\
\hline Higher secondary and above & 71 & 46.7 \\
\hline \multicolumn{3}{|l|}{ Occupation } \\
\hline Homemaker & 77 & 50.7 \\
\hline Business & 31 & 20.4 \\
\hline Service & 39 & 25.7 \\
\hline Labour & 5 & 3.3 \\
\hline Participate in cervical cancer screening program & 4 & 2.6 \\
\hline
\end{tabular}

Table 2: Awareness of respondents regarding cervical cancer $(\mathbf{n}=152)$

\begin{tabular}{lcc}
\hline Risk factors of cervical cancer * & Frequency & Percentage \\
\hline Poor personal hygiene & 88 & 57.9 \\
\hline Early age of sexual intercourse & 51 & 33.6 \\
\hline Multiple sex partner & 90 & 59.2 \\
\hline Having sexually transmitted infections & 52 & 34.2 \\
\hline Smoking & 18 & 11.8 \\
\hline Common signs \& symptoms of cervical cancer * & & 41.4 \\
\hline Increased foul smelling vaginal discharge & 63 & 14.5 \\
\hline Bleeding after sexual intercourse & 22 & 8.6 \\
\hline Blood spots or light bleeding between periods & 13 & 28.3 \\
\hline Menstrual bleeding is longer \& heavier & 43 & 8.6 \\
\hline Bleeding after menopause & 13 & 54.6 \\
\hline Common preventive measures of cervical cancer* & & 46.7 \\
\hline Maintain personal hygiene & 83 & 38.8 \\
\hline Avoid multiple sex partner & 71 & 21.1 \\
\hline Regular cervical cancer screening & 59 & 19.1 \\
\hline Early treatment of STls & 32 & 29 \\
\hline Avoid early age(before 16 years) of sexual intercourse & & \\
\hline
\end{tabular}

Multiple responses * 
Table 3: Awareness of respondents regarding cervical cancer screening $(n=152)$

\begin{tabular}{|c|c|c|}
\hline Variables & Frequency & Percentage \\
\hline Correct meaning of cervical cancer screening & 68 & 44.7 \\
\hline \multicolumn{3}{|l|}{ Type of test for cervical cancer screening } \\
\hline Pap test & 65 & 42.8 \\
\hline \multicolumn{3}{|l|}{ When to start for cervical cancer screening } \\
\hline When to sexual active & 28 & 18.4 \\
\hline Time interval for cervical cancer screening $\mathbf{3}$ yearly & 9 & 5.9 \\
\hline \multicolumn{3}{|l|}{ Best time for cervical screening (pap test) } \\
\hline Within $10-20$ days of menstrual period & 33 & 21.7 \\
\hline \multicolumn{3}{|l|}{ Practice regarding cervical cancer screening ( $n=152)$} \\
\hline Done cervical cancer screening & 48 & 31.6 \\
\hline \multicolumn{3}{|l|}{ How many times have you been screened } \\
\hline One time & 29 & 60.4 \\
\hline Two times & 11 & 22.9 \\
\hline Three times & 8 & 16.7 \\
\hline \multicolumn{3}{|l|}{ Reason for performing screening* } \\
\hline Preventive measure & 26 & 54.2 \\
\hline Diagnostic purpose & 25 & 52.1 \\
\hline Health worker recommendation & 20 & 41.7 \\
\hline Arranged health camp & 2 & 4.2 \\
\hline \multirow[t]{2}{*}{ Level of awareness } & Inadequate $\mathbf{n}(\%)$ & Adequate $\mathrm{n}(\%)$ \\
\hline & $126(82.9)$ & $26(17.1)$ \\
\hline Practice & $34(70.8)$ & $14(29.2)$ \\
\hline
\end{tabular}

Multiple responses *

\section{DISCUSSION}

Different screening techniques for cervical cancer have led to a significant reduction in morbidity and mortality from the disease. Various screening techniques have been introduced for early detection of cervical cancer in Nepal. For instance, Papanicolaou smear screening has been reported to be a good method for detecting early cervical cancer ${ }^{5}$.

The findings of the current study revealed that all of the respondents had heard about cervical cancer. This finding was inconsistent with the result reported by Shrestha where $65.7 \%$ of women had heard about cervical cancer. The fact that this study was conducted in a tertiary centre in capital of Nepal where women are at better access to acquiring information, could be the reason for large proportion of women having heard about cervical cancer ${ }^{8}$.

This study shows that the most common source of information on cervical cancer was media and only a few respondents got information from health professional. Similar results were found in a study conducted by Malibari in Saudi; where the majority women got knowledge from social media (75.6\%) and only few numbers acquire their information from doctors $(4.6 \%)^{9}$. Regarding risk factors of cervical cancer, more than half of the respondents, $59.2 \%$ were aware that multiple sexual partners is a risk factor of cervical cancer. Where in a study of Ali, $45 \%$ mentioned multiple partners as the most common risk factor ${ }^{10}$.

In present study, $41.4 \%$ of the respondents were aware that increased foul smelling vaginal discharge is the main sign and symptom of cervical cancer. Finding is consistent with the study conducted by Thapa where $44.2 \%$ of the respondents mentioned increased foul smelling vaginal discharge as the main sign and symptom of cervical cancer ${ }^{11}$.

In the present study, $44.7 \%$ of the respondents had given correct response regarding meaning of cervical cancer screening, $18.4 \%$ had awareness that one should start cervical screening after becoming sexually active. This finding are slightly different with the study done by Shrestha in Chitwan, Nepal which revealed that 56.3\% of the respondents had knowledge regarding meaning of cervical cancer screening, $25.0 \%$ knew the correct age 
to start screening ${ }^{12}$.This study showed that $5.9 \%$ were aware that screening should be done every three years. Similar finding was showing a study done by John where $5.2 \%$ knew that screening should be done in every 3 years ${ }^{13}$.

In this study, $42.8 \%$ of the respondents were aware that Pap smear is the screening test for cervical cancer. But, study done by Shrestha in Kathmandu showed $53.0 \%$ respondents knew that pap smear ia a screening test $\mathrm{t}^{14}$. Accordingly, 21.7\% knew screening should be done 1020 days of menstruation which was inconsistent with the finding of Shrestha that showed $34.0 \%$ knew that screening should be done 10-20 days of menstruation ${ }^{12}$.

According to the findings, $31.6 \%$ had performed cervical screening. This finding is inconsistent with the study conducted by Shrestha in which $18.8 \%$ had performed cervical cancer screening ${ }^{12}$.

According to the findings, $60.4 \%$ respondents had performed cervical cancer screening one time, 22.9\% two times and $16.7 \%$ three times. Finding is consistent with the findings of Shrestha which showed $33.3 \%$, $22.2 \%$ and $16.7 \%$ had performed cervical cancer screening once, twice and three times ${ }^{12}$.

\section{REFERENCES}

1. Ferlay J, Shin HR, Bray F,Forman D,Mathers C, Parkin DM. Estimates of worldwide burden of cancer in 2008: GLOBOCAN 2008. Int Jor Cancer. 2010; 127(12). [DOI]

2. Gadducci A, Barsotti C, Cosio S, Domenici L, Riccardo Genazzani A. Smoking habit, immune suppression, oral contraceptive use, and hormone replacement therapy use and cervical carcinogenesis: A review of literature. Gynecol Endocrinol. 2011;27(8):597-604. [DOI]

3. Kaku M, Mathew A, Rajan B. Impact of socioeconomic factors in delayed reporting and late stage presentation among patients with cervix cancer in a major cancer hospital in South India. Asian Pac J Cancer Prev. 2008;9(4):589-94. [PubMed]

4. Walboomers JM, Jacobs MV, Manos MM, Bosch FX, Kummer JA, Shah KV. Human papillomavirus is necessary cause of invasive cervical cancer worldwide. J Pathol. 1999; 189(1):12-9. [DOI]

5. Gyawali B, Keeling J, Teijlingen EV, Dhakal L, Aro AR. Cervical cancer screening in Nepal: ethical
This study revealed that only $17.1 \%$ had adequate knowledge regarding cervical cancer screening. The finding is inconsistent with the finding of Singh that showed $32.7 \%$ of the respondents had adequate knowledge ${ }^{15}$.With respect to practice, $70.2 \%$ had inadequate practice. The finding is similar with the study conducted by Shrestha that is $72.2 \%{ }^{12}$.

\section{CONCLUSION}

This study concluded that majority of women had inadequate awareness regarding cervical cancer screening and almost three fourth of the women need to improve practice regarding cervical cancer screening. The level of awareness regarding cervical cancer screening is influenced by the education level of women. The introduction of different screening techniques for cervical cancer has led to a significant reduction in morbidity and mortality from the disease. Thus there is need to conduct awareness program on screening for cervical cancer and developing screening programs at the community as well as in national level.

\section{ACKNOWLEDGEMENTS}

We are thankful to Department of Obstetrics and Gynaecology of Kathmandu Medical College Teaching Hospital for helping us in carrying out this study. Our special thanks go to all the respondents of the study for their kind cooperation.

considerations. Medicolegal and Bioethics. 2015;16(5)1-6. [DOI]

6. Koirala BP. Memorial Cancer Hospital. Annual Report. Bharatpur, Chitwan: 2014.

7. Pradhan N, Giri K, Rana A. Cervical cytological study in unhealthy and healthy looking cervix. Nepal Journal of Obstetrics and Gynecology. 2016; (2):427. [DOI]

8. Shrestha J, Saha R, Tripathi N. Knowledge, attitude and practice regarding cervical cancer screening amongst women visiting tertiary center in Kathmandu, Nepal. Nepal Journal of Medical Science. 2013;2(2):85-90.[DOI]

9. Malibari SS, Knowledge about Cervical Cancer among Women in Saudi Arabia. The Egyptian Journal of Hospital Medicine 2018 Vol. 70 (10), 1823-5. [FullText]

10. Ali SF, Ayub S, Manzoor NF, Azim S, Afif M. Knowledge and awareness about cervical cancer and its prevention amongst interns and nursing staff in tertiary care hospitals in Karachi, Pakistan PLoS ONE2010; 5(6) e11059. [DOI] 
11. Thapa N, Maharjan M, Petrini AM, Shah R, Shah S, Maharjan N, Shrestha N. Knowledge, attitude, practice and barriers of cervical cancer screening among women living in mid-western rural, Nepal. Journal of Gynaecologic Oncology. 2018;29(4). [DOI]

12. Shrestha S, Dhakal P. Knowledge, Attitude and Practice Regarding Cervical Cancer Screening Among Women Attending a Teaching Hospital, Bharatpur, Chitwan. J Fam Reprod Health 2017; 11(1): 18-23. [PubMed]
13. John J. Knowledge, attitude, practice and perceived barriers towards screening for premalignant cervical lesions among women aged 18 years and above, in songea urban, Ruvuma. [Internet] 2011[cited 2018 July 12]. [FullText]

14. Singh E, Seth S, Rani V, Srivastava DK. Awareness of cervical cancer screening among nursing staff in a tertiary institution of rural India. J Gynecol Oncol. 2012; 23:141-6. [PubMed] 